\title{
Mu-Type Opioid Receptor
}

National Cancer Institute

\section{Source}

National Cancer Institute. Mu-Type Opioid Receptor. NCI Thesaurus. Code C118985.

Mu-type opioid receptor (400 aa, $\sim 45 \mathrm{kDa}$ ) is encoded by the human OPRM1 gene. This protein plays a role in G protein-coupled receptor signaling. 